\title{
POR ENTRE O PENSAR SOBRE E O VIVER DAS CRIANÇAS INDÍGENAS KAINGANG
}

\author{
Silvia Maria Alves de Almeida ${ }^{1}$ \\ Patrícia de Moraes Lima²
}

\begin{abstract}
RESUMO: Este artigo tem como objetivo percorrer por entre os "fragmentos" do campo da pesquisa, que se inscreve numa etnografia, a qual nos permite pensar, repensar, visitar e revisitar o campo numa relação de proximidade com os sujeitos crianças da pesquisa, num tempo maior e a partir do que significam as crianças indígenas de suas experiências. Com objetivo de problematizar a trajetória de pesquisadoras e os conhecimentos produzidos sobre as crianças indígenas, bem como as narrativas que se constituem em "verdades" sobre como concebemos as crianças Kaingang na aldeia e cidade, consideramos algumas das leituras que aproximam um "outro olhar" ao que está em diálogo na pesquisa - as crianças indígenas Kaingang e suas relações com a aldeia e a cidade, numa tentativa de problematização acerca destes conhecimentos produzidos.
\end{abstract}

Palavras-chave: Crianças. Indígenas. Território. Alteridade. Verdade.

\section{BETWEEN THE THINKING ABOUT AND THE LIVING OF THE KAINGANG INDIGENOUS CHILDREN}

\begin{abstract}
This article aims to go through among the research field "fragments", which is part of an ethnographic, which allows us to think, rethink, visit and revisit the field in a proximity relationship with the subjects of research children, longer time and from what means indigenous children of their experiences. In order to problematize the trajectory of researchers and the produced knowledge about indigenous child, as well as the narratives that are constituted in "truths", about how we to conceive the kaigang child into the village and the city, we consider some of the readings that approach "another look" that is in dialogue in the research - the indigenous child and your relationship with the village and the city,

${ }^{1}$ Pedagoga e Psicóloga. Doutoranda em Educação da UFSC. E-mail: silvia@unochapeco.edu.br

2 Doutora em Educação pela UFRS. Docente do Centro de Educação da UFSC. E-mail:
\end{abstract} patricia.demoraeslima@gmail.com 
in an attempt to problematize about these produced knowledge.

Keywords: Children. Indians. Territory. Otherness. Truth.

\section{POR ENTRE EL PENSAR Y EL VIVIR DE LOS NIÑOS INDÍGENAS KAINGANG}

RESUMEN: Este artículo tiene como objetivo revisar los "fragmentos" del campo de investigación, que es parte de una etnografía, que nos permite pensar, repensar, visitar y volver a visitar el campo en una relación cercana con los niños de la investigación, en un tiempo más largo y de lo que los niños indígenas quieren decir de sus experiencias. Con el fin de problematizar la trayectoria de los investigadores y el conocimiento producido sobre los niños indígenas, así como las narraciones que constituyen "verdades" sobre cómo concebimos a los niños Kaingang en el pueblo y la ciudad, consideramos algunas de las lecturas que se acercan a una "otra mirada" lo que está en diálogo en la investigación: los niños indígenas Kaingang y sus relaciones con el pueblo y la ciudad, en un intento de problematizar este conocimiento producido.

Palabras clave: Niños. Indígenas. Territorio. Alteridade. Verdade.

\section{Introdução}

Ao tecer uma escrita etnográfica, percorremos entre as ideias, as anotações, os registros, as memórias, as leituras e o próprio pensamento para delinear caminhos que nos colocam diante de indagações que dizem: como a pesquisa nos constituiu na relação com as infâncias e crianças indígenas Kaingang? O caminho que percorremos compôs-se de escolhas que se fizeram pela etnografia, inconclusas e intensas, ao defrontar-nos com os conhecimentos e com o que pensamos das crianças indígenas por entre o lugar vivido e aquele que pensamos para elas, entre a aldeia e a cidade.

O campo, passa a ser pensado no decorrer do tempo, quando do contato da pesquisadora ${ }^{3}$ com as comunidades indígenas no oeste de Santa Catarina, desde o ano

\footnotetext{
${ }^{3}$ Vale ressaltar que este é um trabalho sob orientação da professora Dr. Patrícia Moraes de Lima, em nível de doutorado e versa sobre os registros de campo provenientes da pesquisa- "Crianças indígenas Kaingang: modos de vida entre a aldeia e a cidade" - que envolve a pesquisadora no campo da pesquisa
} 
de 2008, antes mesmo da formalização e sistematização da pesquisa que se inscreve no doutorado em Educação, no ano de 2017. O contato é decorrente de processos de formação profissional na área da educação com os adultos indígenas e da presença de adultos e crianças indígenas nas rodoviárias das cidades, por onde transitavam com seus artesanatos, em que a presença das crianças se fazia, porém muitas vezes despercebida pela pesquisadora. Esse tempo da pesquisadora com os povos indígenas emergiu em muitas indagações iniciais: Pensava eu que estava "preparada" para discutir as questões que envolvem as crianças e as instituições criadas para atendê-las, porém minha bagagem não indígena, com conceitos, saberes e conhecimentos me levavam a dizer e pensar numa criança e na formação de professores distantes da trajetória até aquele momento (Pesquisadora, 2017).

Parte da pesquisa aconteceu na aldeia e parte na cidade, quando então acompanhamos as crianças e suas famílias na comercialização do artesanato. Após o contato e confiança dos adultos e crianças para com a presença da pesquisadora em seu cotidiano na aldeia, partimos para concomitantemente estar com eles na cidade, porém alguns registros da pesquisa na cidade se compõem da presença de outras crianças e famílias que não aquelas da aldeia Kaingang, definida como campo desta pesquisa.

O campo foi sendo tateado e conhecido antes de uma entrada mais permanente da pesquisadora na aldeia, pois a princípio faríamos primeiramente a entrada pela via da rodoviária para depois seguir o caminho da aldeia. Porém, percebemos que as relações entre pesquisadora e indígenas eram passageiras, se davam em um tempo curto na rodoviária, em que as famílias ficavam pouco tempo e o vínculo se constituía de desconfiança e fragilidade. Repensamos então e definimos que a entrada se daria pela aldeia para construção de vínculo e de uma presença cotidiana da pesquisadora 
para aqueles adultos e crianças na aldeia.

Nesse sentido, a pesquisa desta escrita se inscreve marcada de nós e o outro, um outro, pesquisadoras e crianças indígenas Kaingang "percebidas" pelas mãos da etnografia. O texto se delineia diante do desafio de pensar e problematizar o próprio pensar das pesquisadoras, por entre o "pensamento ocidental", não indígena, produzido e que se produz nas e pelas relações de poder que se estabelecem com as crianças indígenas e nas práticas sociais que se constituem na aldeia e na cidade, enquanto produtoras de crianças e adultos. Nas palavras de Lima (2015, p. 95), destacamos para o que nos interroga: "[...] a perspectiva predominante de captura da infância e o aligeiramento que temos ao dizê-la em nossos processos de pesquisa, marcam os diferentes discursos que atribuímos à condição infantil, seus espaços e suas temporalidades."

Os caminhos pela etnografia possibilitaram-nos estar com as crianças Kaingang, desde 2017, na aldeia. As primeiras idas foram mais espaçadas e de muito diálogo com cacique, lideranças e adultos a fim de esclarecer questões acerca do que tratava a pesquisa, sendo que o tempo e contato com as crianças percorreu por um tempo maior de proximidade e de relações de confiança entre pesquisadora-crianças-adultos. Dentre as leituras que selecionamos, elas nos permitem confrontar primeiramente os conhecimentos que produzimos e produzido pelas diversas instituições sobre as formas de como pensar as infâncias e as crianças, neste caso, as crianças indígenas Kaingang, o que nos recoloca em uma outra relação com as crianças e com os conhecimentos que temos produzidos sobre elas.

As referências que se pautam para esta escrita não pressupõem desconsiderar a infinidade de outras leituras que se apresentam para dialogar com os povos indígenas, as infâncias e as crianças. Dentre as escolhas estão as leituras que mais se 
aproximam desse diálogo, neste momento de nossa caminhada enquanto pesquisadoras, circunscrevemos algumas ideias dos estudos de Kohan (2007), Lopes (2013), Santos (1999), Foucault $(2004,2011,2013)$, dentre outros que aqui contribuem na problematização dos discursos e narrativas que se produzem acerca das relações das crianças indígenas com a aldeia e a cidade.

Inicialmente, percorremos por algumas leituras que nos possibilitam posicionarmos as infâncias indígenas como condição da produção social, cultural, de um tempo e espaço constituídos, para, então, adentrarmos nas relações entre as crianças indígenas e os não indígenas Kaingang na aldeia e na cidade. Considerando o vivido e o pensado para elas, seguindo na problematização das "verdades", dos discursos, das relações de poder que se estabelecem na constituição dos sujeitos crianças e adultos indígenas Kaingang, sujeitos desta pesquisa.

\section{Das infâncias e crianças indígenas Kaingang}

[...] que o nosso já sabido pensamento não insista em antecipar e deixe para nosso encontro com a infância pensar. Tal início exige, então, abrir nossa sensibilidade para pensar com a infância, de iguais para iguais, despojandonos do que nossos saberes já capturaram, do que já conhecem, dos pontos de chegada que já pensaram para a educação da infância na língua adulta da filosofia (KOHAN, 2007, p. 133).

Discorremos neste fragmento do texto de algumas ideias e pensamentos que nos são provocadores ao emergir para outras relações com o conhecimento produzido sobre as crianças e suas infâncias, para outras ontologias que rompem com uma visão unificadora do ser criança - criança indígena Kaingang. Para este diálogo, revisitamos algumas questões sobre a problematização e a constituição da verdade no pensamento ocidental e do nosso pensar sobre a emergência dos conceitos de criança e infância; dos conhecimentos produzidos que subjetivam e objetivam os sujeitos 
infantis; do revisitar a memória numa relação de romper com os conhecimentos produzidos acerca dos povos indígenas e do devir criança em outras relações com a cidade e o não indígena, na busca do encontro com a infância indígena Kaingang para pensá-las.

\begin{abstract}
Foi então que aos poucos e naquele instante fui me dando conta do lugar onde estava, [...]. Entendia que não seria possível continuar com minha "verdades" e "saberes" não indígenas somente, e que também não bastava somente debruçar-me pela teoria já produzida por estas e nestas comunidades, era precisar ir além, estar lá, com eles, romper posturas e saberes, conceitos e preconceitos a fim de me aproximar e ganhar confiança daqueles com quem iria passar bastante tempo de meus dias (Pesquisadora, 2017).
\end{abstract}

Ao habitar as infâncias indígenas enquanto pesquisadoras, nos inscrevemos pelas leituras e caminhos que se fazem pela etnografia, numa escrita que nos permite uma aproximação àquilo que é de mais significativo às crianças indígenas Kaingang nas suas relações com a aldeia e a cidade. Nesse sentido, compartilhamos uma questão que nos acompanha há algum tempo, desde nosso contato com esse campo, seja pelas leituras ou pelo próprio campo da pesquisa: "Como as crianças indígenas gostariam que escrevêssemos o que diz respeito a elas e delas? Por onde as crianças começariam a contar e escrever suas histórias?".

A escrita nos remete a um compromisso ético para com as crianças e os povos indígenas, traz uma complexidade que "rompe" estruturas e pensamentos historicamente determinados como "verdades", se propõe a pensar a posição do etnógrafo que escreve sobre e com as crianças indígenas, o que denota implicações políticas, de tomada de decisões, de escolhas minuciosas por aquilo que se descreve ao etnografar o tempo e espaço das crianças indígenas em suas relações com a aldeia e a cidade. 
Como romper com as "verdades" e que escrita permite ao etnógrafo textualizar as narrativas e saberes indígenas frente as suas experiências? Que composição escrita é essa que narra crianças e adultos indígenas em suas relações com as culturas em diálogo e problematizam acerca do que é definido pelos conhecimentos não indígenas sobre os indígenas? Em contato com uma das anciãs ${ }^{4}$ na aldeia, que nos coloca a pensar na produção da escrita e do que registramos e pensamos sobre os indígenas, esta conta sobre o tempo em que não havia a presença dos não indígenas na aldeia, cita que seu povo utilizava as ervas para os cuidados com a saúde das crianças e de seu povo, e com a vinda dos não indígenas, menciona "nós não temos mais como decidir por aquilo que acreditamos, seguimos muitas vezes o que é dito pelos não indígenas" (Anciã, 2017).

Ao não compreendermos e não indagarmos, enquanto adultos, as infâncias e as crianças indígenas, e neste sentido o que somos e temos para olhar e pensar diante de povos indígenas, criamos manuais, instituições, protocolos dos mais variados, distantes das culturas indígenas, com o intuito de explicar e "traduzir" tudo aquilo que os subjetiva e objetiva em suas relações com o mundo e que não é de nosso domínio pela razão. Temos que percorrer o pensamento adulto, acadêmico, ocidental e as instituições criadas para atender as crianças, na sua problematização e ruptura com aqueles saberes que nos foram sacralizados, normatizados, para construir outras relações e saberes com as infâncias indígenas Kaingang, numa relação de alteridade, que nos indica "[...] a problematização das categorias científicas que historicamente construímos para compreender e atuar junto à criança" (GOUVÊA, 2011, p. 549).

Nesse sentido, apontamos para esse autor, que nos chama a atenção acerca da relação adultos e crianças, com destaque para a questão da alteridade e do

\footnotetext{
${ }^{4}$ Ancião na cultura indígena é considerado aquele que tem mais conhecimentos e experiências em relação às questões da cultura.
} 
estranhamento pelo desconhecido. Em suas palavras

\begin{abstract}
A infância, por um lado, remete-nos a um estranhamento, a uma relação com o mundo marcada pela diferença em relação ao adulto [...]. A alteridade da infância não é absoluta, o outro habita em nós, nos constitui e se pronuncia, através da memória, remetendo-nos a um passado que ainda persiste e insiste. Entre o desconhecimento e a profunda identificação, situamo-nos em relação à infância, tentamos compreendê-la, significá-la (GOUVÊA, 2011, p. 549).
\end{abstract}

Pensar a partir da alteridade nos remete a um outro olhar e prática social sobre a relação adultos e crianças, adultos e adultos e crianças e crianças, indígenas e não indígenas, pesquisadoras e crianças, por entre a aldeia e a cidade. Kohan (2007, p. 37) nos convida a pensar o estrangeiro, o outro, aquilo e aquele que não somos para pensar a alteridade, "[...] vou tentar sair desse lugar em que costumamos colocar o estrangeiro, o estranho, o outro: o lugar do fora, do exterior, da falta, da ausência, da impotência." No caso desta pesquisa, o estrangeiro nos constituía naquilo que pensávamos das crianças, dos adultos, de suas relações com o território da aldeia e da cidade, da paisagem, do lugar, de nossa "falta" naquilo que não conhecíamos dos povos indígenas e das infâncias e que pensávamos conhecer. No decorrer da pesquisa, o pensamento habitava muitas dúvidas em relação ao que se tinha para pensar as crianças na aldeia e na cidade:

- Como as cidades recebem as crianças indígenas?

- De onde vêm as crianças e seus familiares? Quem as acompanha?

- O que trazem as famílias e as crianças indígenas para a cidade?

- Quanto tempo ficam na cidade? E por quê? Há um período específico para sua vinda?

- Por que as famílias indígenas nesse tempo na cidade fazem da rodoviária sua estadia?

- Como se dá a presença das crianças na rodoviária? É o ano todo? Tem algum período em especial?

- Como as crianças percebem e recebem a presença do não indígena na rodoviária/cidade?

- O que pensam as crianças por estar na rodoviária? Quais sentimentos têm em relação a esse lugar? (Pesquisadora, 2017).

Argumentos Pró-Educação, Pouso Alegre, Dossiê - Infâncias e crianças

indígenas, quilombolas e de outros povos tradicionais: (re) existências e 
A aldeia se constitui de diversas relações entre adultos e crianças, as maiores, pequenas e bem pequenas, elas se deslocam de um lugar a outro com autonomia, segurança e conhecimento acerca do lugar por onde passam. Acompanhadas de adultos e outras crianças, transitam pelas instituições presentes na aldeia - a escola, a unidade de saúde, a igreja. Nas relações que estabelecem com o outro, as crianças observam curiosamente e cuidadosamente os adultos que lhes são estranhos e que não pertencem àquele lugar, algumas se aproximam e outras se mantêm distantes.

Ao chegar à aldeia, nas primeiras idas, as relações se constituíram de estranhamento entre nós, de longe as crianças me observavam e depois de um tempo voltavam as suas atividades. O olhar de pesquisadoras aos poucos passava pela desconstrução de um "modelo" de infância e crianças, racionalizado pela academia e pela cultura não indígena: "a ausência estava em nós que tentávamos olhar pelo viés de uma outra cultura" (Pesquisadora, 2018). O caminho permaneceu pela desconstrução de nosso olhar, numa relação permanente de alteridade para com o outro. Sobre a alteridade, destacamos também as contribuições de Lima (2015, p. 95): "Defendo que é pelo exercício da alteridade que nos desentendemos dessa tarefa de contribuir para o governo da infância e passamos, a inverter e converter sobre nós mesmos a pergunta: o que mesmo nos educa a infância?"

Partindo das leituras de Kohan (2007, p. 10), nos posicionamos para uma outra relação ao pensar a infância, atribuímos a ela uma imagem de pensamento. Para o autor, a infância é "uma condição da experiência", numa relação com a vida e com a temporalidade que desestabiliza, rompe com padrões e normas constituídas socialmente. O autor cita em suas leituras a existência de "duas" infâncias, uma que se propõe a pensar e dizer de um modelo de infância, que trata de normas e de uma cronologia da vida, que aparece nas práticas de muitas instituições. E a outra infância 
que ele denomina como "minoritária". "Essa é a infância como experiência, como acontecimento, como ruptura da história, como revolução, como resistência e como criação" (KOHAN, 2007, p. 95). Para o autor, essas infâncias estão relacionadas entre si, elas não se excluem ao pensar as crianças e infâncias. "As linhas se tocam, se cruzam, se enredam, se confundem" (p. 95).

Enquanto condição da experiência, as infâncias indígenas, no contato com as materialidades e as formas de vida que se apresentam na cidade e que são definidas pelos não indígenas como "ideal", se colocam numa outra relação com o lugar, com as situações ali vividas, estas geralmente diferem do padrão "aceito" socialmente das formas de ser e viver estabelecidos a uma criança e a um adulto. Essas experiências têm uma relação muito próxima às formas de viver na aldeia, conforme observado nesse fragmento.

Segui próximo ao Mercado Público e encontrei mais duas famílias, havia muitas crianças juntas, com aproximadamente 4 a 6 anos. Uma delas no tempo em que estive ali, estava sendo amamentada no seio de sua mãe, prática essa que tenho observado entre os indígenas, crianças entre dois, três a quatro anos sendo amamentadas com leite materno (Pesquisadora, 2018).

Nesse sentido, problematizamos: o que nos perguntamos sobre o que pensamos sobre as crianças indígenas na cidade e seus modos de ser e viver as infâncias? De onde vem esse pensar crianças e povos indígenas que se diz sabedor e constituidor de verdades sobre o outro? Como e o que definimos para as crianças enquanto práticas de cuidado, atenção na relação com os adultos? Que "verdades" estão colocadas no momento que estabelecemos a cada faixa etária um tipo de comportamento e aprendizado? Kohan (2007, p. 62) nos remete a pensar sobre a "experiência que o esvaziamento da verdade abre". Que verdades estão colocadas sobre as crianças indígenas nos vários discursos e instituições que a remetem a uma condição de "falta"? Como suas experiências são relatadas quando as verdades sobre 
elas se colocam acima dessas experiências? Como abrir-se para o esvaziamento das verdades sobre as crianças e infâncias indígenas?

Na relação ciência, razão e verdade, o que é validado como conhecimento nos discursos ocidentais produzidos sobre as crianças indígenas em seus processos de subjetivação e objetivação? Entender os modos de subjetivação que nos fazem assujeitados a normas, a regras, que não foram por nós criadas, mas por outro, que nos diz sobre como devemos ser, nos portar e viver, nos coloca diante da coragem da verdade. Nessa perspectiva, mencionamos as contribuições de Gros, que apontam para

\begin{abstract}
Duas estéticas da existência, dois estilos absolutamente diferentes de coragem da verdade: a coragem de se transformar lentamente, de fazer manter um estilo em uma existência movente, de durar e persistir; a coragem, mais pontual e mais intensa, da provocação, a de fazer aflorar por sua ação verdades que todo mundo conhece, mas que ninguém diz, ou que todo mundo repete, mas que ninguém se dá o trabalho de fazer viver, a coragem da ruptura, da recusa, da denúncia. [...] exigência de uma ética que persegue a verdade e denuncia a mentira (GROS, 2004, p. 165-166).
\end{abstract}

Pensar a vida num outro modo de produzi-la, pela recusa e denúncia, pela problematização dos saberes produzidos sobre os sujeitos e suas relações com o poder, com aqueles discursos que se produzem acerca de suas vidas e realidade, tem como exigência uma relação ética com a verdade. Apontamos aqui, brevemente, as contribuições de Foucault sobre a parrhesia, para entender o governo de si e do outro, da relação do sujeito para com o poder e com a verdade.

Nas palavras de Foucault (1995, p. 239)

Talvez, o objetivo hoje em dia não seja descobrir o que somos, mas recusar o que somos. Temos que imaginar e construir o que poderíamos ser para nos livrarmos desse 'duplo constrangimento' político, que é a simultânea individualização e totalização própria às estruturas de poder moderno. A conclusão seria que o problema político, ético social e filosófico de nossos dias não consiste em tentar liberar o indivíduo do Estado nem das instituições do Estado, porém nos liberarmos tanto do Estado quanto do tipo 
de individualização que a ele se liga. Temos que promover novas formas de subjetividade através da recusa deste tipo de individualidade que nos foi imposto há vários séculos.

A subjetivação e a objetivação dos saberes sobre os sujeitos de como devem ser e viver nas mais diversas esferas constituem uma identidade professada e operada em discurso. O sujeito se constitui como alguém regido pela norma e o biopoder. "Os processos de objetivação são acompanhados de processos de subjetivação a partir dos quais o indivíduo dá seu assentimento e reconhece ser objetivado [...] incapaz de pensar por si mesmo sem a obediência a outrem" (CANDIOTTO, 2016, p. 31).

Em conversa com uma das anciãs na aldeia, esta relatou como processos de subjetivação e objetivação se colocam em relação com as experiências das crianças no decorrer de seu crescimento e de suas vidas, desde o nascimento, quando então são vacinados, cita que: "mesmo quando não queremos fazer a vacina somos obrigados, a enfermeira do posto vai em nossa casa e nós temos que fazer" (Anciã, 2017). Que processos de subjetivação e objetivação estão atravessados e são produzidos na aldeia e na cidade sobre as crianças indígenas em suas experiências? Não estamos aqui e nem será nossa intenção tratar da importância ou não da vacinação, nossa intenção está em pensar e problematizar formas de viver que aos indígenas Ihes foram subjetivados e objetivados por outras culturas. Como se produzem os conhecimentos dessas relações e sujeitos que colocam em jogo os discursos de verdade?

Essa problematização da verdade tem dois lados, dois grandes aspectos. Um
lado está preocupado em assegurar que o processo de raciocínio está correto
para determinar se uma declaração é verdadeira (ou preocupar-se com a
nossa capacidade de ter acesso à verdade). E o outro lado está preocupado
com a questão: Qual é a importância para o indivíduo e para a sociedade de
dizer a verdade, de conhecer a verdade, de ter pessoas que dizem a verdade,
bem como saber como reconhecê-las? No lado que se preocupa em
determinar como garantir que uma afirmação é verdadeira temos as raízes
da grande tradição da filosofia ocidental, que eu gostaria de chamar de
'analítica da verdade'. E no outro lado, preocupado com a questão da 
importância de dizer a verdade, de saber quem é capaz de dizer a verdade, e saber por que devemos dizer a verdade, temos as raízes do que poderíamos chamar a tradição 'crítica' no Ocidente (FOUCAULT, 2013, p. 112).

Estamos dispostos a pensar sobre o que pensamos das crianças e infâncias indígenas na cidade? Estamos dispostos a pensar sobre quem somos e sobre o que pensamos do "outro" criança? Assim,

[...] pensar a infância desde outra marca, ou melhor, a partir do que ela tem, e não do que the falta: como presença, e não como ausência; como afirmação, e não como negação, como força, e não como incapacidade. Essa mudança de percepção vai gerar outras mudanças nos espaços outorgados à infância no pensamento e nas instituições pensadas para acolhê-las (KOHAN, 2007, p. 101).

Lima (2015, p. 98) argumenta sobre o desafio aos pesquisadores acerca de problematizar o que se produziu sobre a infância como "algo ainda por nós desconhecido", o que para a autora pressupõe "[...] reconhecer a importância de outras adjacências conceituais para compreendermos melhor o conceito de alteridade e consequentemente o próprio conceito de infância". Para Kohan (2007, p. 82), "abandonar o que se é, de abrir espaço para ser outro do que se é". De pensar a história que constitui os povos indígenas em sua trajetória, de "mexer" com a memória para pensar a relação do não indígena com os povos indígenas. Nessa linha de pensamento, apontamos para as contribuições de Lima e Nazário (2015, p. 766), que indagam sobre "[...] o que, a partir das nossas interpretações frente a esta, nos interroga, nos desestabiliza, nos incita na busca ativa para novas e profundas relações e interpretações".

As primeiras idas à aldeia desestabilizaram aquilo que pensávamos e que buscávamos encontrar no campo/aldeia - as crianças indígenas - enquanto pesquisadoras dialogávamos sobre: "onde estão as crianças?”. As crianças estavam lá, 
não havia um lugar e nem um tempo certo para encontrá-las. Percebemos que nosso olhar, imbricado em modos de ser crianças não indígenas havia construído um lugar para as crianças que naquele momento passava a ser interrogado por uma falta que não era da aldeia e muito menos dos povos indígenas, a "falta" estava em nossos conhecimentos e saberes sobre as crianças que ali habitam aquele lugar.

Na relação estabelecida com as crianças indígenas, somos surpreendidos pelas experiências e pensares das crianças, daquilo que ressignificam destas na aldeia e ou na cidade. Suas experiências no decorrer da pesquisa foram na sua maioria registradas pela observação e alguns poucos diálogos entre pesquisadora e crianças, pois as crianças assim como os adultos são falantes da língua, algumas crianças começam a falar o português somente com a entrada na escola, outras falam ainda quando estão em casa.

Como o dia estava muito quente, ouço barulho, algazarra de crianças pequenas, aparentam ter entre 4 e 5 anos de idade, procuro de onde vem o barulho e logo avisto crianças brincando dentro de um tanque de lavar roupas, conversavam entre si, no idioma, o que me impossibilitou compreendê-las, além do que expressavam pelos gestos e pelo corpo movimentos de jogar água para o lado, para cima e uma na outra. Ouvia-se uma voz que parecia orientar as crianças, era de um adulto, que logo entrou para dentro de casa (Pesquisadora, 2018).

Nesse sentido, trazemos as contribuições de Kohan (2007) acerca de como, enquanto adultos, seguidamente em nossas relações com as crianças buscamos interpretar o que nos dizem, buscamos ainda explicar seu pensamento e transformar em "verdades", "[...] usar nossos corriqueiros poderes e saberes, nossas velhas artimanhas, para traduzir aquela língua, a princípio, incompreensível. Seria bastante fácil se colocar no lugar de decifrador do enigma" (KOHAN, 2007, p. 126).

Outro aspecto considerado por Kohan (2007) para pensar a infância é acerca das leituras de Deleuze e Parnet (1988), ao apontar para o conceito de devir como a relação 
entre sujeitos, eventos, situações, ideias, que são mobilizadas à criação de outra relação não datada e nem determinada por algum tipo de norma ou modelos de ser e viver, pensar, mas pelas possibilidades de criação de outras relações. Nesse sentido, Kohan (2007, p. 96) entende o devir criança como "uma forma de encontro que marca uma linha de fuga a transitar, aberta, intensa". Nesse sentido, discorremos para as seguintes questões: Que devires as crianças indígenas Kaingang, quando de sua presença na cidade, criam nas relações que estabelecem com o não indígena e com os lugares por onde circulam? De que forma o encontro entre crianças indígenas e adultos não indígenas causa estranhamento pela "falta" visível aos olhos de quem construiu uma imagem de uma criança branca, ocidental, "saudável" e que segue um padrão "normal" de desenvolvimento?

Nas palavras de Kohan (2007, p. 102), há uma necessidade de "tirar a infância de alguns lugares que a tradição Ihe consagra há muito tempo". Nessa linha de pensamento, indagamos: que relações, práticas e conhecimentos estão dados sobre o ser infância que se rompem em suas verdades diante do instituído como modelo de crianças? Como nos relacionamos com as crianças indígenas quando estão na cidade acompanhando seus familiares na comercialização do artesanato? Que tipo de exigência definimos para uma aproximação com o estrangeiro criança indígena quando de sua presença na cidade? Kohan $(2007$, p. 117) nos permite pensar nessa relação quando problematiza: "Trazer o estrangeiro à terra do outro, à outra terra, não significaria matar sua estrangeiridade?"

As políticas instituídas acerca das infâncias "condenam" as crianças indígenas a viverem e se constituírem uma outra infância que não as significam, assim como cita Kohan acerca da condenação de Sócrates em sua época por ser e viver em desacordo à época? 
Quiçá seu gesto estrangeiro e infantil mereça certa atenção pelo que revela: que o assassinato do estrangeiro infantil pela política instituída coloca a estrangeiridade e a infância num lugar não só muito mais arriscado e exposto, mas também potente e afirmativo; afinal, mostra-as como ameaça, fuga, a afirmação de outros mundos, outras políticas (KOHAN, 2007, p. 124).

Destacamos, ainda, em Kohan (2007), a questão da memória, em que o autor cita as "Memórias inventadas" de Manoel de Barros, a qual recorremos para pensar entre as memórias dos povos indígenas acerca do lugar que as crianças ocupam em suas relações com natureza, símbolos, rituais, cultura e da intimidade que crianças e adultos têm para com a aldeia diferem em relação com a cidade.

Talvez, se abríssemos a memória em uma dimensão iônica do tempo, ela pudesse ser, ao contrário, algo da ordem da ruptura com o passado e com a temporalidade contínua e sucessiva do antes e do depois, talvez a memória possa ser algo da ordem do afastamento do passado, da recusa de outro tempo e da instauração de um novo tempo para pensar, de um novo início para pensar o tempo e de um tempo para pensar (KOHAN, 2007, p. 88-89).

Precisamos revisitar a memória que nos constitui para perguntar sobre as infâncias constituídas por leituras e saberes que as tematizam e que dizem sobre elas tratados, normas e protocolos que as objetivam e subjetivam em seus modos de ser e viver a aldeia e a cidade. Destacamos que é preciso revisitar os conhecimentos, a memória para a produção de uma outra relação ontológica e epistemológica com os saberes que tratam as crianças e infâncias dos povos indígenas. Nas palavras de Kohan (2007, p. 99): “A infância também tem a ver com revisitar certos lugares como se fosse a primeira visita". Revisitar o pensamento das instituições, dos especialistas, das academias, do senso comum, para abrir-se a um outro/novo encontro com as crianças e infâncias indígenas, diante das possibilidades de uma outra/nova relação entre adultos, crianças, indígenas e não indígenas. 


\section{O lugar pensado e o vivido: entre as crianças indígenas Kaingang, a aldeia e a cidade}

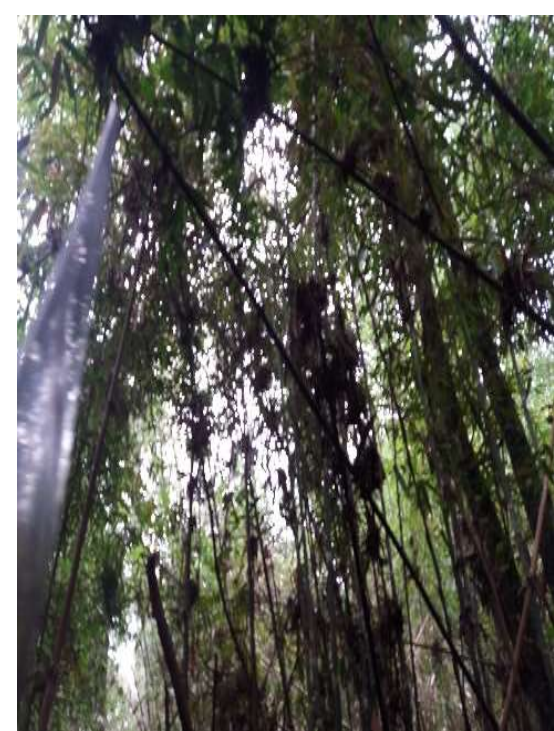

Figura 1 - Acervo pessoal. Fonte: Almeida (2018).

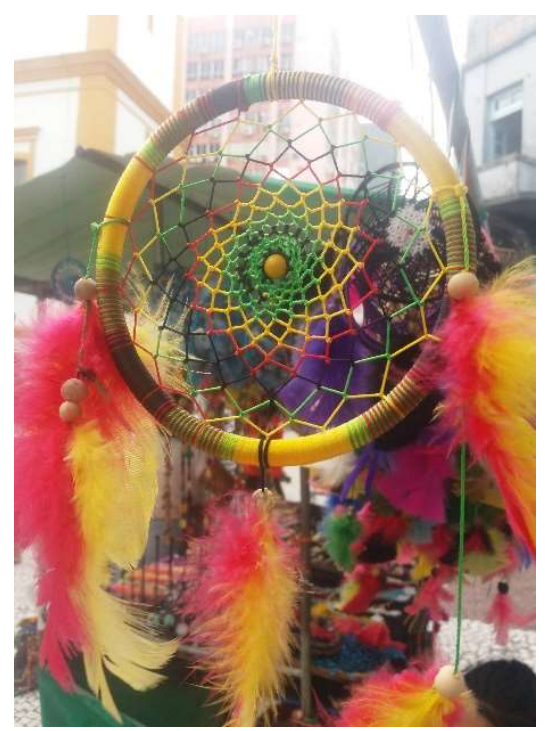

Figura 2 - Acervo pessoal. Fonte: Almeida (2018).

Por entre a aldeia e a cidade encontramos as crianças indígenas Kaingang e suas infâncias em relações com o outro, pelas experiências que subjetivam e objetivam seus modos de ser, viver e pensar a si mesmas e ao outro. As crianças indígenas Kaingang acompanham seus familiares à cidade durante o ano todo. Sempre que eles se deslocam até a cidade, na maioria das vezes, as crianças os acompanham, nos meses em que estão de férias escolares, as famílias que comercializam o artesanato organizam seus pertences, as crianças e partem para diferentes regiões do estado de Santa Catarina.

Quando há festas e eventos em outros municípios mais próximos, a aldeia as famílias também se deslocam com as crianças e o artesanato, mas logo retornam devido às atividades escolares das crianças. Portanto, a permanência das crianças 
Kaingang na cidade junto de seus familiares se localiza numa temporalidade distinta aos períodos de férias, feriados, e outros períodos em que há maior produção do artesanato e das ervas medicinais que seguem o curso da natureza e do tempo. Os conceitos de lugar, território, espaço, aldeia e cidade se configuram em importantes elementos na compreensão das relações que se constituem pelas crianças indígenas Kaingang entre o vivido e o que se é pensado para elas viverem, nas relações entre a aldeia e a cidade. Não temos aqui a pretensão de conceituar esses termos, mas destacar alguns elementos que contribuem na leitura que delineamos.

Primeiramente, partimos de algumas indagações que sinalizam pensar os lugares vividos pelas crianças e aqueles que entendemos como necessários à sua educação: Como as crianças indígenas habitam a aldeia e a cidade? Nas suas percepções, como estes lugares se apresentam? Em que diferenças a cidade se apresenta para as crianças? Como a cidade está organizada para acolher as crianças e adultos indígenas quando de sua comercialização do artesanato? Que arranjo espacial se desenha para as crianças indígenas e seus familiares na cidade e que se aproxima dos lugares construídos na aldeia e que são por eles habitados?

Ao chegar à aldeia, logo pela manhã ouço galos cantando, pássaros que voam por entre as árvores, o sol está quente e clareia a manhã, o vento que sopra pelas folhas das árvores não é intenso, mas balança seus galhos levemente, a poeira pela estrada é sinal de que a chuva não habita aquele lugar a algum tempo. Assim compõe-se a aldeia onde vivem as crianças indígenas. As casas estão fechadas logo na entrada, todos parecem dormir. $\mathrm{Na}$ parte central da comunidade algumas casas também se encontram fechadas. [...]As crianças parecem estar em suas casas, muitas delas acompanham seus familiares na venda do artesanato nessa época do ano. Percebo em algumas das casas um sinal de que ali há crianças, pois os varais de roupas estão repletos de pequenas roupas. Algumas crianças devem estar dormindo, talvez algumas assistindo, como conheço poucas pessoas não consigo com mais exatidão dizer onde se encontram as crianças logo cedo (Pesquisadora, 2018).

Chego a rodoviária, por volta das 13:20 [...]. Ao entrar no estacionamento da rodoviária, encontro produções em artesanato dos indígenas. No local não

Argumentos Pró-Educação, Pouso Alegre, Dossiê - Infâncias e crianças

indígenas, quilombolas e de outros povos tradicionais: (re) existências e 
havia ninguém, mesmo assim tomei a liberdade em fotografar o espaço em que estavam presentes a matéria prima, os cestos, balaios, artefatos de natal, colchões, cobertores, pertences particulares das pessoas que haviam deixado naquele lugar seus pertences. Entre o barulho dos carros, das pessoas falando, ouvi um barulho que vinha do alto da rodoviária, era um senhor indígena que cortava uma taquara, sentado à sombra, fazia um dia bastante quente e ensolarado (Pesquisadora, 2017).

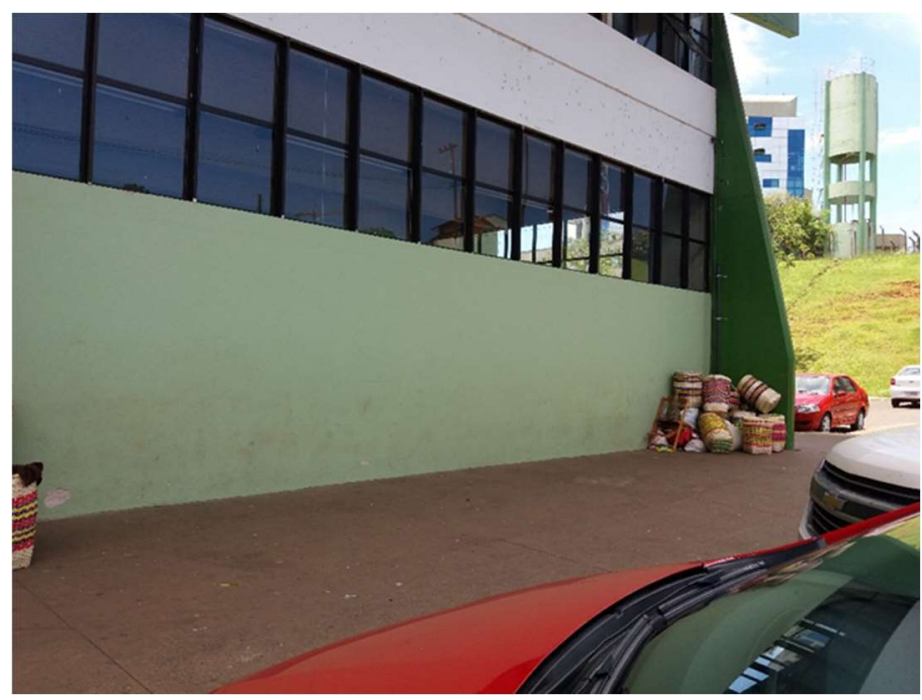

Figura 3 - Acervo pessoal

Fonte: Almeida (2017).

Ao adentramos as leituras de Lopes (2013) acerca da geografia da infância, para apresentar algumas de suas reflexões sobre o conceito de lugar, o autor destaca para diversas mudanças na compreensão destes conceitos - espaço e lugar -, o que nos coloca em outra leitura na percepção do lugar que as crianças habitam, entendido como proveniente de relações afetivas estabelecidas e compartilhadas entre as pessoas. As crianças indígenas no contato com a cidade encontram algumas paisagens que diferem da aldeia, as relações que estabelecem com as pessoas na cidade também se alteram e estão permeadas de outras experiências que diferem daquelas vividas na aldeia. A cidade coloca as crianças e adultos numa relação de "falta" de condições a sua estada durante o tempo que ali permanecem. 
No dia 30 de novembro, no período matutino, me dirigi até a rodoviária de Xaxim, passei próximo e num terreno baldio à frente da rodoviária encontrase um barraco de lona, este habitado por indígenas que estavam na rodoviária, mas que tem sido habitado por outros que vêm à cidade. Na cerca havia também pequenos cestos expostos, algumas taquaras, material utilizado para confecção do artesanato. Parecia não haver ninguém nesse momento. No final da tarde não havia mais sinais de que haveria pessoas por ali (Pesquisadora, 2017).

Lopes e Vasconcellos (2006), acerca da relação criança e lugar, reiteram que:

Toda criança é criança de um lugar. Do mesmo modo, toda criança é criança em algum lugar. Ou seja, existe na produção das culturas infantis uma ancoragem territorial que não apenas emoldura o contexto no qual se edifica a infância, mas, para além disso, oferece o próprio substrato material à produção da existência (LOPES; VASCONCELLOS, 2006, p. 110).

As particularidades do lugar, do ambiente que vivem as crianças indígenas na aldeia, as produzem e as diferenciam enquanto sujeitos crianças conhecedoras deste lugar, suas relações com o lugar se pautam pela autonomia, liberdade e conhecimento do espaço, pois circulam com confiança por entre casas, ruas e paisagem que se desenha na aldeia. Como o espaço construído pelas crianças e adultos indígenas na aldeia os colocam em relação com a natureza, com a cultura, com os símbolos e significados que os constituem? O espaço da cidade lhes possibilita estabelecer que relações com os lugares por onde circulam? E na cidade, o que é de acesso às crianças indígenas deste lugar? Que territórios são esses que se diferenciam e que habitam as crianças e adultos indígenas?

De acordo com Santos (1999, p. 13), quando dialogamos com o conceito de território, precisamos pensar para além da materialidade, pois sua abrangência envolve as relações que ali se estabelecem. "O território é o lugar em que desembocam todas as ações, todas as paixões, todos os poderes, todas as forças, todas as fraquezas, isto é, onde a história do homem plenamente se realiza a partir das manifestações da sua existência". 
A presença das crianças indígenas Kaingang na cidade junto de seus familiares na comercialização do artesanato passa a ser visível em que momento, a quem e de que forma? Quando "interessa” ver as crianças indígenas na cidade? Que lugares as crianças transitam? Como se relacionam nesses lugares e o que criam, inventam para compor sua presença, sua permanência na cidade? Entre as cores e o movimento da cidade, dos artesanatos, as crianças circulam pela cidade e buscam seu espaço.

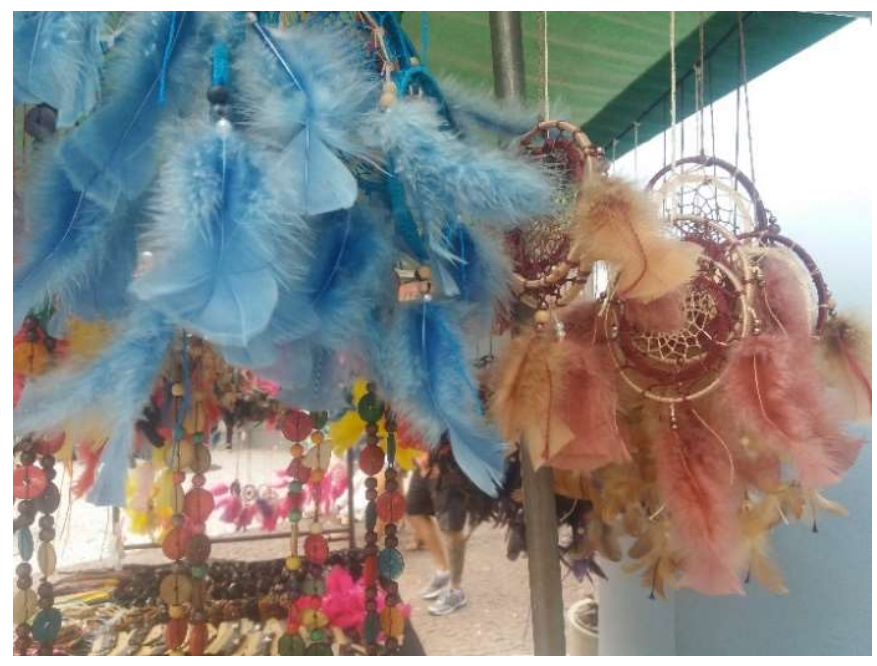

Figura 4 - Acervo pessoal. Fonte: Almeida (2019).

A rodoviária passa a ser um espaço habitado pelos adultos e crianças indígenas quando estes vêm à cidade para a comercialização do artesanato. Algumas cidades dispõem de outros espaços para a organização de "acampamentos", onde as famílias, de posse de suas materialidades, organizam o local para sua permanência durante esse tempo na cidade.

Encontro com Ricardo e Mateus próximos ao supermercado na cidade, ainda não os conhecia, percebo que são crianças indígenas pois estão com filtros do sonho nas mãos, elas me olham e eu as cumprimento, com um sorriso me pedem: "você tem algum "troquinho" pra dar". Olhei para eles, sorri, e eles insistiram em pedir se eu não teria nada para lhes dar. Aproveitei o momento para me aproximar e perguntei de onde eles eram, disseram que eram de 
Nonai, perguntei se conheciam outras aldeias, Ricardo disse que era de lá. Ficou um pouco confusa a informação, pois haviam dito que eram de Nonai, então perguntei se conhecia a professora de lá, disse que sim, que era professora dele.

- Onde vocês estão? (Pesquisadora)

- Na rodoviária. (Ricardo)

- Quem está com vocês? (Pesquisadora)

- A vó, minha mãe e tio. (Ricardo)

- Posso ir lá depois conversar com vocês e com eles? (Pesquisadora)

Ricardo disse que eu poderia, mas que sua mãe estava na venda do artesanato e que não estaria lá. Nos despedimos e eles seguiram (Pesquisadora, 2017).

No percurso da história, as crianças indígenas constituem uma "nova história" na medida em que sua relação com a cidade passa a ser questionada, problematizada pelo viés da pesquisa na busca de um diálogo com as linhas de fuga que as constituem. Que linhas de fuga são essas que as infâncias e as crianças indígenas anunciam em suas relações com a cidade, com o não indígena? O que das crianças indígenas e de sua presença na cidade nos "incomodam" e que a qualquer custo queremos "enquadrálas" num modelo de ser criança?

Kohan (2007) nos coloca a pensar nas infâncias pela desconstrução de modelos de ser criança e daquilo que as constituem em suas existências não pensadas ainda pelo pensamento, o que, nas palavras do autor, destacamos.

Quem sabe possamos encontrar um novo início para outra ontologia e outra política da infância naquela que já não busca normatizar o tipo ideal ao qual uma criança deva se conformar, ou o tipo de sociedade que uma criança tem que construir, mas que busca promover, desencadear, estimular nas crianças e em nós mesmos essas intensidades criadoras, disruptoras, revolucionárias, que só podem surgir da abertura do espaço, no encontro entre o novo e o velho, entre uma criança e um adulto (KOHAN, 2007, p. 97-98).

Estar com as crianças indígenas Kaingang na aldeia e ou na cidade tem nos ensinado muito delas e das relações que estabelecem nestes lugares. Aprendemos um pouco do que pensam, como vivem, como se relacionam com tudo aquilo que na aldeia 
conhecem das plantas, dos animais, dos açudes, das pessoas, do artesanato e na cidade nos ensinam a repensar o lugar, o espaço construído, o território, as relações com os não indígenas e os lugares que construímos para elas a partir de uma visão de criança/infância.

\section{Discurso e poder: constituição dos sujeitos crianças da aldeia a cidade}

Com minha escrita, percorro o corpo dos outros, faço incisões nele, levanto os tegumentos e as peles, tento descobrir os órgãos e, trazendo-os à luz, fazer enfim aparecer esse foco de lesão, [...] esse algo que caracterizou sua vida, seu pensamento [...] (FOUCAULT, 2016, p. 45).

Primeiramente, escrever e pensar o pensamento ocidental sobre os povos indígenas é como percorrer, fazer incisões e fazer aparecer as lesões do que constitui esse pensamento, as ideias, as relações, o que não se constitui em uma tarefa simples, transitar pelas leituras, a história que perpassa a suas ideias. Isso nos colocam em outros modos de pensar o que foi escrito, dito, produzido e pensado sobre o próprio pensamento e a constituição do sujeito, que somos e que se fazem existir em seus diversos discursos e enunciados sobre nós e o outro - crianças indígenas.

A composição do texto se destaca para a relação do sujeito consigo e com o que se produz sobre si, e as verdades que se definem na sua cultura e que dizem deste sujeito, mesmo que os valores de verdade deste sujeito se contradizem, num determinado momento da história, para aquele momento atuam como verdadeiras e os constituem sujeitos. Nessa perspectiva, sobre o interrogar-se o próprio pensar e a constituição do sujeito, Foucault (2004, p. 235) problematiza "[...] em que condições alguma coisa pôde se tornar objeto para um conhecimento possível, como ela pôde ser problematizada como objeto a ser conhecido, a que procedimento de recorte ela pôde ser submetida, que parte dela própria foi considerada pertinente".

O que propomos está para com a relação que estabelecemos com a "verdade" 
sobre as crianças e povos indígenas Kaingang, para pensarmos em outras relações que interrogam esse pensar a si mesmo e ao outro. De acordo com Kohan (2007, p. 82-83): "Seria um exercício de pensamento que busca abrir esse pensamento ao ainda nãopensado $[\ldots]^{\prime \prime}$.

Diante dessas questões, indagamos: Que discursos e/ou enunciados são produzidos e produzem os sujeitos crianças em suas relações com a aldeia e a cidade e que são tomados como produtores de verdade e se tornam objetos de conhecimento, validados ou não pela ciência? Conforme Kohan (2007, p. 52): "Tratase de instaurar uma outra política, em primeiro lugar no pensamento, uma política da experiência e não da verdade, uma política de interrogação permanente sobre a possibilidade e as formas da própria política, que a desinstale do lugar da impossibilidade." Na continuidade, o autor reitera sua ideia e destaca para a experiência do estrangeiro como uma viagem "[...] de uma experiência de pensamento que inquieta e impede continuar a pensar da maneira como se pensava" (p. 54).

Num diálogo permanente com o campo da pesquisa, colocamos em interrogação o que nos constitui enquanto sujeitos e que a todo momento se questiona, problematiza, nos coloca em uma outra "relação consigo mesmo", de assumir os riscos "ao dizer a verdade", mas quem teria condições de dizer a verdade? A aproximação e o contato com o campo da pesquisa nos colocou em tensionamento com as "verdades" produzidas por uma cultura ocidental, não indígena, adultocêntrica, que nos constituem enquanto pesquisadoras ao interrogar: Como olhar e estar com as crianças indígenas a partir do que as constituem culturalmente e nos constituem como não indígenas? Que discursos são enunciados e dizem o que se define como verdade ao sujeito? Quais as consequências deste dizer daquilo que se definiu como verdade?

Ao abordar essas e outras questões, buscaram-se alguns elementos que contribuem numa leitura filosófica e que problematiza os modos de viver, ser, pensar 
ocidental que nos constituem, com o destaque para a produção do discurso, da verdade ao cuidado de si e da constituição do sujeito. Para Foucault, olhar para o passado a pensar a filosofia que resulta nos modos que se constituem o pensamento na atualidade o coloca na composição de uma atitude crítica do pensamento ocidental. Daí o conceito de problematização pressupor a existência de diferentes formas de elaborar, de dizer sobre algo, de uma resposta que se constrói em relação a uma dada situação. Nesse sentido, é preciso se perguntar sobre a razão de aquela resposta estar colocada e ser aceita como verdade: "Como e por que certas coisas [...] tornaram-se um problema?" (FOUCAULT, 2013, p. 113).

Diante do conceito de problematização indicado por Foucault, é possível pensar e se perguntar sobre em que momento as crianças indígenas passaram a ser legitimadas e consideradas sob verdades validadas que unificaram saberes e culturas? Por que o acompanhamento das crianças a cidade tornou-se um problema jurídico e social? $\mathrm{Na}$ pesquisa de campo, narrativas produzidas em reportagem televisiva, divulgada pelos meios de comunicação em Santa Catarina, sobre as crianças indígenas Kaingang que acompanham os familiares a cidade, buscam explicar a sua presença enunciando-a como "exploração do trabalho infantil".

A reportagem anuncia, que a escolha por uma escola e aldeia para desenvolver um projeto que visa discutir o trabalho infantil nas escolas em Santa Catarina, com os alunos, seria o motivo de as crianças acompanhar os familiares, o que remete ao trabalho infantil "[...] durante as férias escolares muitos pais levam os filhos pra venderem o artesanato em outras regiões do estado". Enunciados produzidos pelos não indígenas, que operam sobre a realidade das crianças indígenas e da cultura dos povos indígenas, são geralmente divulgados como uma verdade sobre a cultura indígena, o que aqui problematizamos no sentido das "verdades" produzidas.

O discurso opera com regras de quem o domina, não havendo uma unicidade 
de discurso sobre determinada questão, ele está ligado a um campo de forças e disputas, por isto precisa estar situado no lugar que ele se inscreve. Em relação ao sujeito, ele está exposto a discursos que dizem quem ele é e o lugar que ele ocupa a partir do discurso que se faz dele. No discurso é possível encontrar as interdições que se ligam ao desejo e ao poder, e ao princípio de exclusão, em que o discurso do sujeito passa a ser rejeitado, não considerado naquele momento, dependendo do lugar que ocupa e que fala (FOUCAULT, 2011).

A partir dos discursos modernos de sujeito, sociedade e realidade, produziramse enunciados de verdade que têm o poder de verdade,

[...] a história crítica do pensamento não é uma história das aquisições nem das ocultações da verdade; é a história da emergência dos jogos de verdade: é a história das 'veridições', entendidas como as formas pelas quais se articulam, sobre um campo de coisas, discursos capazes de serem ditos verdadeiros ou falsos: quais foram as condições dessa emergência, [...] seus efeitos no real e a maneira pela qual, ligando um certo tipo de objeto a certas modalidades do sujeito, ela constituiu, por um tempo, uma área e determinados indivíduos, o a priori histórico de uma experiência possível (FOUCAULT, 2004, p. 235).

Em sua obra, o autor nos faz refletir sobre ditos verdadeiros ou falsos, que estão nos jogos de verdade e relações de poder/saber. Na pesquisa de campo, enunciados são produzidos pelo não indígena sobre as crianças indígenas que acompanham os familiares na cidade e buscam explicar a sua presença enquanto os familiares fazem a venda do artesanato. Os enunciados operam sobre a realidade e são aceitos, divulgados como verdade da cultura não indígena.

Dessa leitura e análise, produz-se um saber que vai gerar medidas, discursos, formas de operar sobre a vida das crianças e adultos indígenas pela ação do poder de um discurso biopolítico, do controle da população, do cuidado com a vida e das relações de poder. "E a partir daí toda uma série de técnicas de observação entre as quais a estatística, evidentemente, mas também todos os grandes organismos 
administrativos, econômicos e políticos, tudo isso é encarregado dessa regulação da população" (FOUCAULT, 1982, p. 37).

Conforme Walkerdine (1995, p. 209), “[...] formas de poder que colocam o governo como parte de uma vigilância minuciosa e detalhada [...] da população, de forma que a população a ser governada passa, num certo sentido, a governar a si mesma [...]". Os discursos proferidos permitem que as coisas aconteçam, eles não são externos a nós, pois os produzimos, sendo que alguns são afirmados e outros excluídos, dependendo do lugar que os sujeitos ocupam o possibilitam ou não autorizam a pronunciar aquele discurso. Como opera o discurso produzido sobre as crianças indígenas e as questões culturais da aldeia? O que está colocado no discurso de poder sobre as crianças indígenas ao afirmar-se algo sobre elas? De acordo Foucault (2004, p. 235): “A questão é determinar o que deve ser o sujeito, a que condições ele está submetido, qual o seu status, que posição deve ocupar no real ou no imaginário para se tornar sujeito legítimo deste ou daquele tipo de conhecimento [...]".

Quais as regras discursivas que operam e que se tornam verdade para as comunidades indígenas sobre o acompanhamento e presença das crianças quando da venda dos artesanatos na cidade? Como esse universo se situa nessas relações discursivas que são datadas, representadas, enunciadas, que dizem das crianças indígenas na cidade pelas instituições que tem sobre elas relações de poder? Que imagem construímos das crianças indígenas na cidade quando as vemos na cidade, com artesanato nas mãos, oferecendo junto de seus familiares às pessoas, que enunciados ganham força e espaço frente aos meios de comunicação, ao poder público, ao sistema judiciário considerando essa situação? Como o poder opera no discurso produzido em torno das crianças indígenas? Como os meios de comunicação exercem o governo do outro, de uma outra cultura e o enuncia? O poder está presente na vida dos sujeitos pelos diversos discursos que se estabelecem pelos próprios 
sujeitos, ele se encontra em relação com e entre os sujeitos.

O que está em questão nesses jogos de poder, sutis, um pouco singulares, às vezes marginais? Eles implicam nada mais, nada menos do que o status da razão e da desrazão; implicam o status da vida e da morte, do crime e da lei; ou seja, um conjunto de coisas que ao mesmo tempo constituem a trama de nossa vida cotidiana, e a partir das quais os homens construíram seu discurso da tragédia (FOUCAULT, 2004, p. 45)

Conforme Foucault (2004), os jogos de poder e as relações por eles atravessadas incidem nos sujeitos e seus modos de viver, agora não mais somente produzidos e pensados pelas grandes organizações, instituições, mas pelo próprio sujeito que é capturado por relações que pressupõe o governo de si. O autor destaca que

[...] estamos em um desses momentos em que essas questões cotidianas, marginais, mantidas em um relativo silêncio, atingem um nível de discurso explícito, em que as pessoas aceitam não apenas falar delas, mas entrar no jogo dos discursos e tomar partido em relação a elas (FOUCAULT, 2004, p. 46).

Interpretar o texto, os enunciados, questionar-se sobre o modo como nós vemos a realidade e como somos por ela constituídos, implica em uma relação ética com a verdade, da recusa e do romper com o jogo dos discursos produzidos, com os modos de pensar a verdade, o sujeito e a si mesmo, para constituir outras relações pautadas no cuidado de si. Como em "As Damas de Companhia", de Velásquez, Foucault nos coloca a pensar o quadro na relação com o pintor, o espectador, a linguagem, o espelho e a realidade que se produz sob o olhar de quem está fora para pensar dentro e quem está dentro para pensar fora, como algo que está em aberto para outras leituras, outros modos de pensar, de ver, de relacionar o que é percebido e que pode ser falado a cada momento de outro modo por quem o contempla.

O quadro nos interroga a pensar: como vemos o campo da pesquisa? Que relações estabeleceram com esse campo e os sujeitos que compõem o "quadro" e os "espectadores" que olham o campo e produzem diferentes olhares e interpretações 
sobre esse campo? Como nos afetamos pelo campo e ao que dele é enunciado?

Problematizar o campo e os modos como as verdades subjetivam e objetivam as crianças enunciadas pelas instituições, na aldeia e na cidade, bem como pelos saberes não indígenas e que constituem estes campos de saber/poder em suas relações de poder e verdade. Isso nos coloca em uma outra leitura e relação para com o conhecimento que se anuncia, as crianças indígenas na aldeia e na cidade.

\section{Referências}

CANDIOTTO, C. Sujeito, agonística e seus desdobramentos políticos no pensamento de Michel Foucault. In: NALLI, M.; MANSANO, S. R. V. (org.). Michel Foucault: desdobramentos. Belo Horizonte: Autêntica, 2016. p. 29-40.

DELEUZE, G.; PARNET, C. 0 abecedário de Gilles Deleuze: transcrição integral do vídeo, para fins exclusivamente didáticos. Éditions Montparnasse: Paris, 1988.

FOUCAULT, M. As malhas do poder. Barbárie, Salvador, ano 3, n. 5, p. 34-41, 1982.

. O sujeito e o poder. In: RABINOW, P.; DREYFUS, H. L. Michel Foucault: uma trajetória filosófica (para além do estruturalismo e da hermenêutica). Rio de Janeiro: Forense Universitária, 1995. p. 231-250.

Ditos e escritos. v. V - Estética, Sexualidade, Política. Rio de Janeiro: Forense Universitária, 2004.

Ditos e escritos. v. III - Estética: literatura e pintura, música e cinema. Rio de Janeiro: Forense Universitária, 2011.

. O discurso e a verdade: o significado da palavra Parrhesia. 1a Conferência.

Prometeus, São Cristóvão, ano 6, n. 13, 2013. Disponível em:

https://seer.ufs.br/index.php/prometeus/article/download/1550/1423. Acesso em: 20 maio 2019.

O belo perigo. Belo Horizonte: Autêntica, 2016. 
GOUVÊA, M. C. S. Infantia: entre a anterioridade e a alteridade. Educação e Realidade, Porto Alegre, v. 36, n. 2, p. 547-567, maio/ago. 2011. Disponível em: https://seer.ufrgs.br/educacaoerealidade/article/view/11394/12926. Acesso em: 16 maio 2019.

GROS, F. A parrhesia em Foucault. In: (org.). Foucault: a coragem da verdade (1982-1984). São Paulo: Parábola Editorial, 2004. p. 155-166.

KOHAN, W. Infância, estrangeiridade e ignorância: ensaios de filosofia e educação. Belo Horizonte: Autêntica, 2007.

LIMA, P. M. Infância(s), alteridade e norma: dimensões para pensar a pesquisa com crianças em contextos não institucionais. Currículo sem Fronteiras, v. 15, n. 1, p. 94106, jan./abr. 2015. Disponível em: http://www.curriculosemfronteiras.org/vol15iss1articles/lima.pdf. Acesso em: 21 maio 2019.

LIMA, P. M.; NAZÁRIO, R. Pequenas flores vermelhas: narrativas fílmicas e o que podem pensar sobre a institucionalização da infância?. Revista Atos de Pesquisa em Educação, Blumenau, v. 10, n. 3, p. 749-770, set./dez. 2015. Disponível em: https://proxy.furb.br/ojs/index.php/atosdepesquisa/article/view/5031/3163. Acesso em: 06 maio 2019.

LOPES, J. J. M.; VASCONCELLOS, T. Geografia da infância: territorialidades infantis. Currículo sem Fronteiras, v. 6, n. 1, p. 103-127, jan./jun. 2006. Disponível em: http://www.curriculosemfronteiras.org/vol6iss1articles/lop_vasc.pdf. Acesso em: 19 maio 2019.

LOPES, J. J. M. Geografia da infância: contribuições aos estudos das crianças e suas infâncias. Revista Educação Pública, Cuiabá, v. 22, n. 49/1, p. 283-294, maio/ago. 2013. Disponível em: http://periodicoscientificos.ufmt.br/ojs/index.php/educacaopublica/article/view/915 /716. Acesso em: 12 maio 2019.

SANTOS, M. O dinheiro e o território. GEOgraphia, Rio de Janeiro, v. 1, n. 1, p. 7-13, 1999. Disponível em: https://periodicos.uff.br/geographia/article/view/13360/8560. Acesso em: 13 maio 2019. 
WALKERDINE, V. O raciocínio em tempos pós-modernos. Educação e Realidade, Porto Alegre, v. 20, n. 2, p. 207-226, jul./dez. 1995. Disponível em:

https://seer.ufrgs.br/educacaoerealidade/article/view/71742/40677. Acesso em: 11 maio 2019.

Enviado em: 31/05/2019

Aprovado em: 22/10/2019 